\title{
Capacity of Activated Carbon Derived from Agricultural Waste in the Removal of Reactive Dyes from Aqueous Solutions
}

\author{
Mahboobeh Manoochehri ${ }^{1, \uparrow}$, V. K. Rattan ${ }^{2}$, Ameneh Khorsand ${ }^{3}$ and Homayon Ahmad Panahi ${ }^{1}$ \\ ${ }^{1}$ Department of chemistry, Islamic Azad University, Central Tehran branch, Tehran, Iran \\ ${ }^{2}$ Department of chemical engineering and technology, Panjab University, Chandigarh, India. \\ ${ }^{3}$ Member of Young Researchers Club, Islamic Azad University, Central Tehran branch, Tehran, Iran \\ ^e-mail: mmanooch@yahoo.com \\ (Received January 8, 2010; Accepted May 30, 2010)
}

\begin{abstract}
The study describes the results of batch experiments on the removal of Reactive Yellow 15 (RY15) and Reactive Black 5 (RB5) from synthetic textile wastewater onto Activated Carbon from Walnut shell (ACW). The experimental data were analyzed by the Langmuir, Freundlish, Temkin and Dubinin-Radushkevich (D-R) models of adsorption. The experiments were carried out as function of initial concentrations, $\mathrm{pH}$, temperature (303-333), adsorbent dose and kinetics. The surface area and pore volumes of adsorbent were measured by BET and BJH methods. The findings confirm the surface area (BET) is $248.99 \mathrm{~m}^{2} / \mathrm{g}$. The data fitted well with the Temkin and D-R isotherms for RY15 and RB5, respectively. The most favorable adsorption occurred in acidic $\mathrm{pH}$. Pseudo-second order kinetic model were best in agreement with adsorption of RY15 and RB5 on ACW. The results indicate that walnut shell could be an alternative to more costly adsorbent currently being used for dyes removal.
\end{abstract}

Keywords : Reactive dyes, BET, BJH, Walnut shell, Isotherms

\section{Introduction}

Many industry-produced wastewater contains different types of organic and inorganic pollutants [1]. Generally, the wastewater from printing and dyeing units in a textile plant is rich in color, containing residue of dyes and chemicals [2,3]. Moreover, dyes used may be toxic to aquatic organisms and can be resistant to natural biological degradation [4]. Active azo dyes have double bound of nitrogen to nitrogen $(-\mathrm{N}=\mathrm{N}-)$, which is bounded to an aromatic group [5,6] so, they can produce harmful health effects and it is essential to have a proper method to remove this dyes from wastewater. As a result, the removal of color from waste effluents has become environmentally important [7-9]. Many researchers use cheap and ecofriendly adsorbents to substitute the more expensive, commercially available activated carbons. Such alternatives include: biosorbents, natural materials, agricultural waste and industrial by products [10-12]. Adsorption of organic pollutants onto solid/water interfaces has been found to be an efficient and economically cheap method compared to the other purification and separation methods [13]. This paper reports on the ability of Activated Carbon from Walnut shell (ACW) to remove Reactive Yellow 15 (RY15) and Reactive Black 5 (RB5) from aqueous solutions. The effect of $\mathrm{pH}$, initial dye concentrations, temperature, kinetics and dose of $\mathrm{ACW}$ were investigated. The Langmuir, Freundlich, Temkin and Dubinin-Radushkevich (D-R) were used to fit the equilibrium data. Pseudo first-order and pseudo second-order kinetic models were attempted.

\section{Materials and Methods}

\subsection{Adsorbent}

The walnut shell was obtained from local natural resources. After obtained, fresh walnut shells were washed several times with distilled water to remove surface impurities and then dried at room temperature for one day. The samples were heated and burned and the charcoals were crushed by grinder and then ground to pass through a 100-mesh sieve for further experiments. It was activated to a final temperature of $500^{\circ} \mathrm{C}$ in muffle furnace for six hours. Some physical and chemical properties of walnut shell were showed in Table 1. This was performed by he adsorption of $\mathrm{N}_{2}$ at $77 \mathrm{~K}$ using Micrometrics Surface Area Analyzer (ASAP 2010, Micromerities Inc., USA).

\subsection{Adsorbate}

RY15 (Reactive Yellow 15, C.I. 11859; chemical formula, $\mathrm{C}_{48} \mathrm{H}_{40} \mathrm{~N}_{13} \mathrm{NaO}_{13} \mathrm{~S}_{3}$; Mw, $1172.13 \mathrm{~g} / \mathrm{mol}$ ) and RB5 (Reactive 
Table 1. Physicochemical Properties of ACW

\begin{tabular}{lc}
\hline \multicolumn{1}{c}{ Parameters } & values \\
\hline - Surface Area & $249 \mathrm{~m}^{2} / \mathrm{g}$ \\
BET Surface Area: & $400 \mathrm{~m}^{2} / \mathrm{g}$ \\
Langmuir Surface Area: & $273 \mathrm{~m}^{2} / \mathrm{g}$ \\
\hline Single Point Surface Area at P/P $\mathrm{P}^{0} 0.30325457:$ &
\end{tabular}

- Pore Volume

Single Point Total Pore Volume of pores less than

768.3726 Å Diameter at $\mathrm{P} / \mathrm{P}^{0} 0.97414716$ : $0.153 \mathrm{~cm}^{3} / \mathrm{g}$

- Pore Size

Average Pore Diameter $(4 \mathrm{~V} / \overline{\mathrm{A}} \AA$ A by BET $)$ :

$24.6 \AA$

BJH Adsorption Average Pore Diameter $(4 \mathrm{~V} / \AA): 52.1 \AA$

BJH Desorption Average Pore Diameter $(4 \mathrm{~V} / \AA): 53.3 \AA$

Black 5, C.I. 20505; chemical formula, $\mathrm{C}_{26} \mathrm{H}_{21} \mathrm{~N}_{5} \mathrm{Na}_{4} \mathrm{O}_{18} \mathrm{~S}_{6}$; $\mathrm{Mw}, 975.82 \mathrm{~g} / \mathrm{mol}$ ) were used as the adsorbates in this study. They were all prepared from Alvan Saabet Company in Iran and used without any further purification. The chemical structures of RY15 and RB5, shown in Fig. 1. They have a maximum visible adsorbance at wavelenghs of $415 \mathrm{~nm}$ for RY15 and $598 \mathrm{~nm}$ for RB5.

\subsection{Adsorption studies}

Adsorption of RY15 and RB5 were carried out by a batch technique in aqueous solutions and experiments were conducted to observe the effect of various parameters effect of $\mathrm{pH}$, temperature, amount of adsorbent, initial dye concentrations and kinetics. Adsorption experiments were carried out at various concentrations of dye solutions in the range of $1 \times 10^{-5}$ to $5.5 \times 10^{-5} \mathrm{M}$ by adding a fixed amount of $\mathrm{ACW}(1 \mathrm{~g})$ to a series of $100 \mathrm{~mL}$ conical flasks. The conical flasks were then placed in room temperature for $48 \mathrm{~h}$ and then filtered. The final concentrations of dyes were measured at maximum wavelengths of RY15 and RB5 using a single beam UV-Vis spectrophotometer (Shimadzu, UV1101, Japan). The amount of dye adsorbed onto the adsorbent, $\mathrm{q}_{\mathrm{e}}$ $(\mathrm{mol} / \mathrm{g})$, was calculated by equation:

$$
q_{e}=\frac{\left(C_{0}-C_{e}\right) V}{W}
$$

where $\mathrm{C}_{0}$ and $\mathrm{C}_{\mathrm{e}}(\mathrm{mol} / \mathrm{L})$ are the initial and equilibrium state dye concentrations, respectively. $\mathrm{V}$ is the volume of the solution (L) and $\mathrm{W}$ is the mass of adsorbent used (g).

The effect of ACW dose on the amount of RY15 and RB5 adsorbed were studied by adding different amounts $(0.2,0.4$, $0.6,0.8,1,1.2,1.4$ and $1.6 \mathrm{~g}$ ) of ACW into amount of $100 \mathrm{~mL}$ conical flasks containing a definite volume of fixed initial concentration $\left(3.5 \times 10^{-5} \mathrm{M}\right)$ of dye solutions. The flasks were placed in room temperature for $48 \mathrm{~h}$ and then dye concentrations were measured at equilibrium. The dye removal percentage was calculated using the following relationship:

$$
\text { Removal percentage }=\frac{\left(C_{i}-C_{f}\right)}{C_{i}} \times 100
$$

where $C_{i}$ and $C_{f}(\mathrm{~mol} / \mathrm{L})$ are the liquid-phase concentrations of dye at initial and equilibrium, respectively.

To study the effect of $\mathrm{pH}$ was studied by adjusting the $\mathrm{pH}$ of dye solutions using $1 \mathrm{M} \mathrm{H}_{2} \mathrm{SO}_{4}$ and $1 \mathrm{M} \mathrm{NaOH}$ solutions. The $\mathrm{pH}$ was measured using a $\mathrm{pH}$ meter (PB-11). Experiments were carried out using different initial solution $\mathrm{pH}$ values from 1 to 11 .

To study the effect of temperature, $1 \mathrm{~g}$ sample of ACW was added to each $100 \mathrm{~mL}$ volumes of RY15 and RB5 aqueous solutions at different initial concentrations. The

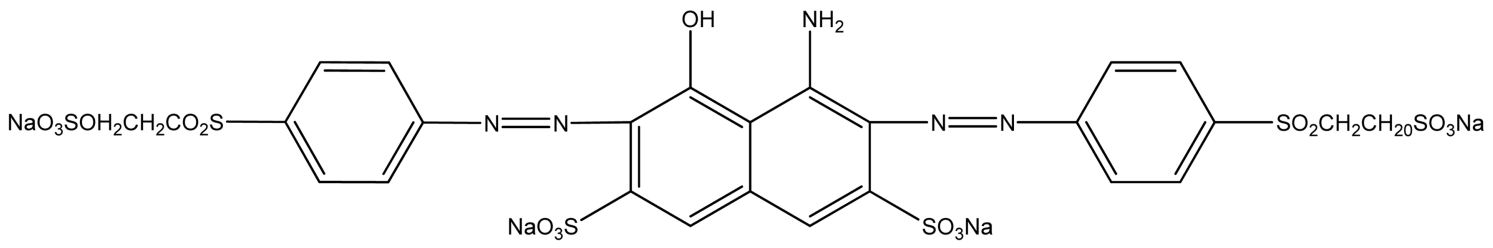

Reactive Black 5

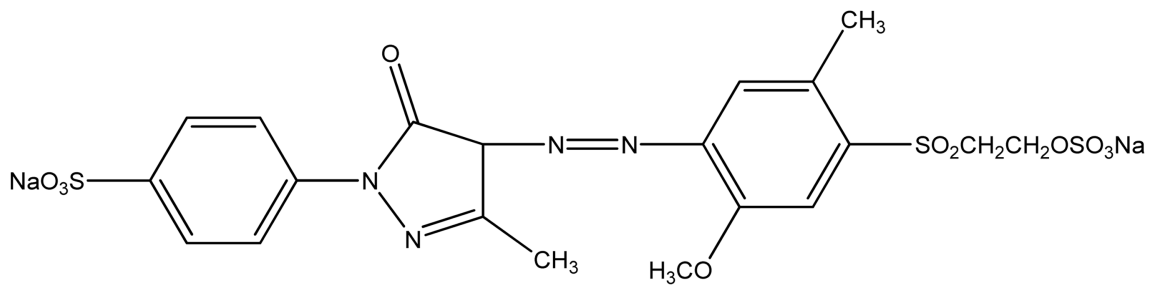

Reactive Yellow 15

Fig. 1. Structures of Reactive Black 5 and Reactive Yellow 15. 


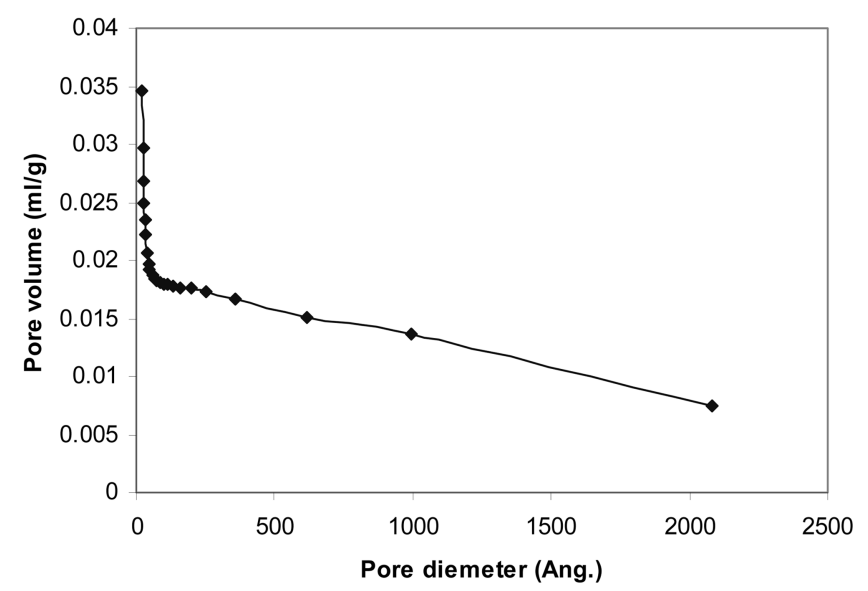

Fig. 2. Pore size distribution of ACW particles.

experiments were carried out at 303 to $333 \mathrm{~K}$. Temperature control was provided by the water bath shaker units.

The kinetic studies were carried out using a mechanical stirrer. The adsorbance of all samples were determined at certain time intervals $(5,10,20,30,40,50,60,70,80,90$ and $100 \mathrm{~min}$ ) during the adsorption process. The amount of adsorption at time $\mathrm{t}, \mathrm{q}_{\mathrm{t}}(\mathrm{mol} / \mathrm{g})$ was calculated by:

$$
q_{t}=\frac{\left(C_{0}-C_{t}\right) V}{W}
$$

where $C_{t}(\mathrm{~mol} / \mathrm{L})$ is the liquid-phase concentration of dye at any time.

\section{Results and Discussion}

\subsection{Characterization of the prepared $A C W$}

The pores in activated carbons are divided into three groups: the micropores with diameters less than $2 \mathrm{~nm}$, mesopores with diameters between 2 and $50 \mathrm{~nm}$, and macropores with diameters greater than $50 \mathrm{~nm}$ [14]. According to Table 1, the $\mathrm{BJH}$ results show that the pores are distributed on the $\mathrm{ACW}$ surface as follows: $13.64 \%$ (micropores), $77.77 \%$ (mesopores) and $8.59 \%$ (macropores). The BET surface area of the prepared ACW is $248.99 \mathrm{~m}^{2} / \mathrm{g}$ with a total pore volume of $0.153 \mathrm{~cm}^{3} / \mathrm{g}$. Fig. 2 shows cumulative pore volume $\left(\mathrm{cm}^{3} / \mathrm{g}\right)$ vs. pore diameter $(A)$. Interestingly, it becomes obvious from this figure that the pore volumes decrease as the pore diameters increase.

\subsection{Effect of adsorbent dose on dyes adsorption}

To optimize the adsorbent dose for the removal of RY15 and RB5 from aqueous solutions, adsorption was carried out with different adsorbent dosage at room temperature. Fig. 3 shows the effect of ACW dose on the removal percentage of

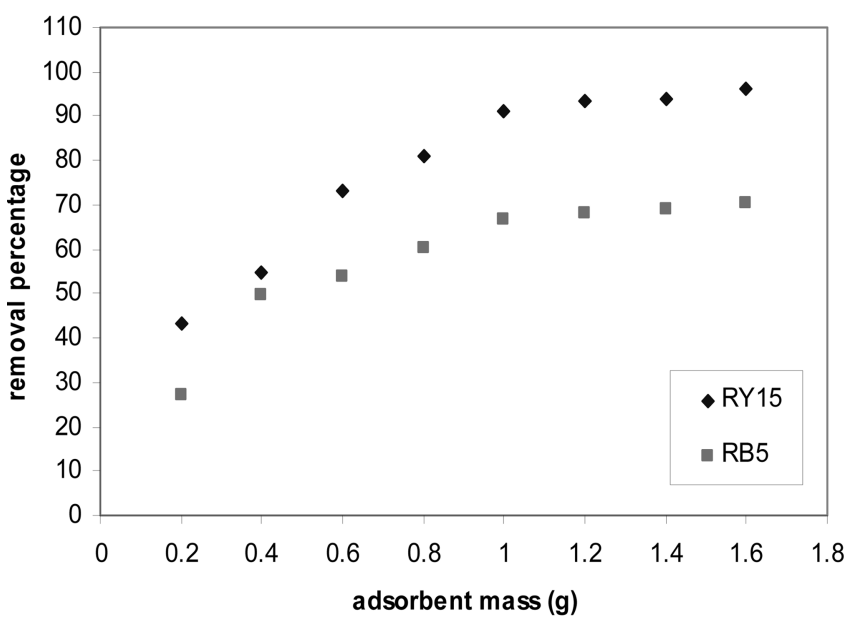

Fig. 3. Effect of adsorption dosage on adsorption of both dyes.

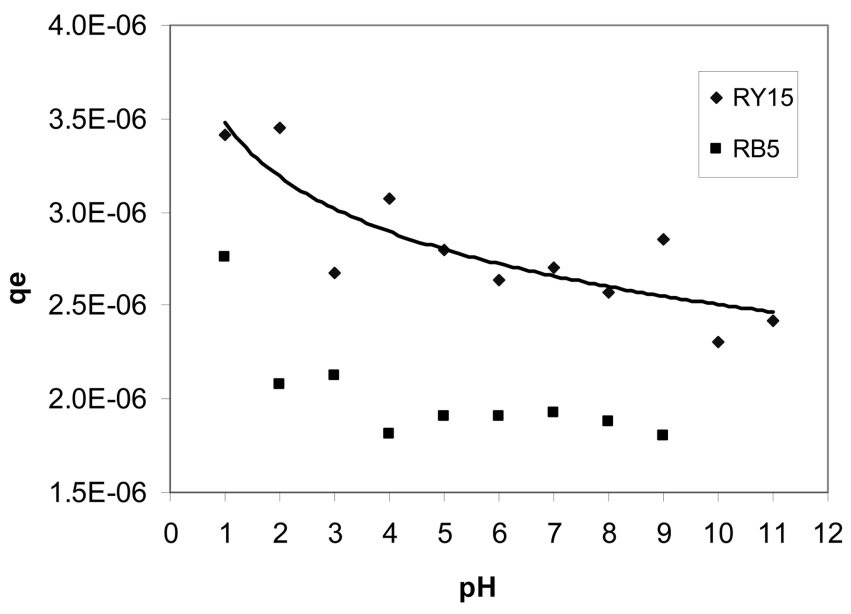

Fig. 4. Effect of $\mathrm{pH}$ on the adsorption of both dyes.

RY15 and RB5. It was observed that the removal of RY15 and RB5 increase up to $1 \mathrm{~g}$ and then it remain almost constant. The increases in colors removal percentage were duo to the increases of the available sorption surface and availability of more adsorption sites. A similar behaviour was reported for the adsorption of methylene blue on peanut hull [15].

\subsection{Effect of $\mathrm{pH}$}

The influence of $\mathrm{pH}$ on adsorption of the two dyes is shown in Fig. 4 and the maximum removal was achieved at $\mathrm{pH}$ 1. In acidic condition, the positive charge dominates the surface of the adsorbent. Thus a significantly high electrostatic attraction exists between the positively charged surface of the adsorbent and negatively charged dye species. This attractive force increases the adsorption chances of dye species onto the surface of the adsorbent. The lower $\mathrm{pH}$ 


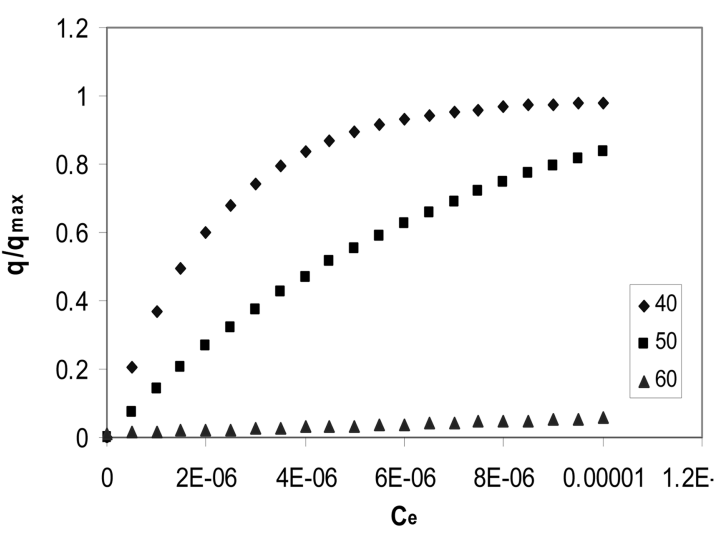

Reactive Yellow 15

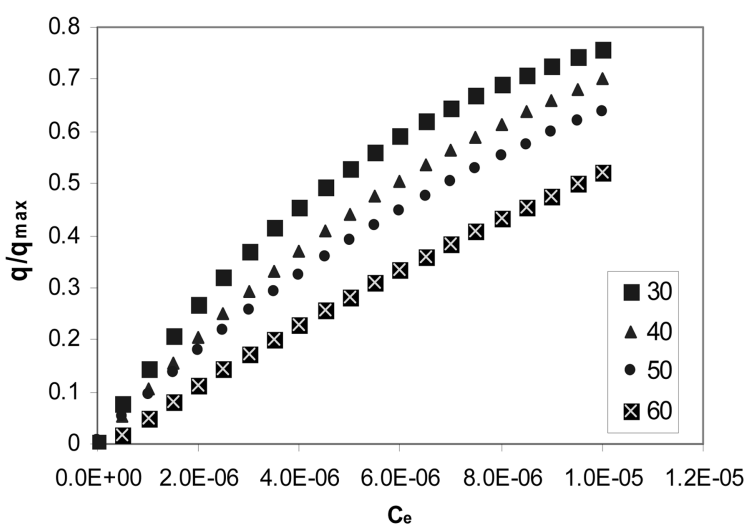

Reactive Black 5

Fig. 5. Effect of temperature on the adsorption of both dyes (values in the box is in ${ }^{\circ} \mathrm{C}$ ).

negatively charged surface site on the adsorbent did not favour the adsorption of RY15 due to electrostatic repulsion but, adsorption of RB5 shows the percent removal remained constant in $\mathrm{pH}=9-5$. A similar result was observed for the adsorption of acid red 14 by soy meal hull [16] and removal of acid dyes using a biosorbent [17].

\subsection{Effect of temperature}

In order to observe the effect of temperature batch adsorption studies were carried out with both dyes. Adsorptions of both dyes were measured at various temperatures (303 333 K). Fig. 5 shows a decrease in adsorption with an increase in solution temperature. Therefore, adsorption of both studied dyes were exothermic and chemisorption in nature.

\subsection{Isotherms modelling}

The adsorption data obtained for equilibrium conditions have been analyzed by using the linear forms of the Langmuir, Freundlich, Temkin and D-R isotherms. The Langmuir adsorption isotherm (Eq. (4)), is based on the assumption [18] that adsorption takes place at specific homogeneous sites within the adsorbent and once a dye molecule occupies a site, no further adsorption take place at that site. The Freundlich isotherm (Eq. (5)), is an empirical equation employed to describe heterogeneous systems [19]. The Temkin equation (Eq. (6)), suggests a linear decrease of sorption energy as the degree of completion of the sorptional centres of an adsorbent is increased. The heat of adsorption of all the molecules in the layer would decrease linearly with coverage due to adsorbent-adsorbate interactions [20]. The D-R isotherm model [21] does not assume a homogeneous surface or constant sorption potential. It was applied to estimate the porosity apparent free energy and the characteristic of adsorption and it has commonly been applied in the following form Eq. (7) and $\varepsilon$ is the Polanyi potential that can be calculated from Eq. (8).

$$
\begin{aligned}
& \frac{1}{q_{e}}=\frac{1}{q_{\max }}+\frac{1}{k_{L} q_{\max }} \frac{1}{C_{e}} \\
& \log q_{e}=\log K_{F}+\frac{1}{n} \log C_{e} \\
& q_{e}=B \ln A+B \ln C_{e} \\
& \ln q_{e}=\ln Q_{m}-K \varepsilon^{2} \\
& \varepsilon=R T \ln \left(1+\frac{1}{C_{e}}\right)
\end{aligned}
$$

where $q_{e}$ is the amount of dye adsorbed on ACW at equilibrium $(\mathrm{mol} / \mathrm{g}), C_{e}$ the equilibrium concentration of dye solution $(\mathrm{mol} / \mathrm{L}), \mathrm{K}_{\mathrm{L}}$ the Langmuir equation constant (Lit/

Table 2. Comparison of the Coefficients Isotherm Parameters by RY15 and RB5 Adsorption Onto ACW

\begin{tabular}{ccc}
\hline Isotherm models & RY15 & RB5 \\
\hline Langmuir & $1 \times 10^{-5}$ & $2.770 \times 10^{-6}$ \\
$\mathrm{q}_{\max }$ & $1.496 \times 10^{+4}$ & $1.756 \times 10^{+4}$ \\
$\mathrm{~K}_{\mathrm{L}}$ & 0.9481 & 0.9282 \\
$\mathrm{R}^{2}$ & & \\
Freundlich & $1.928 \times 10^{-3}$ & 1.293 \\
$\mathrm{~K}_{\mathrm{F}}$ & 1.555 & 0.792 \\
$\mathrm{n}$ & 0.9230 & 0.9274 \\
$\mathrm{R}^{2}$ & 148.413 & 148.413 \\
\hline Temkin & $1.238 \times 10^{+98}$ & $6.193 \times 10^{+}$ \\
$\mathrm{A}$ & 0.9627 & 0.9807 \\
$\mathrm{~b}$ & & \\
$\mathrm{R}^{2}$ & $1 \times 10^{-17}$ & $3 \times 10^{-17}$ \\
$\mathrm{D}-\mathrm{R}$ & $2.424 \times 10^{-6}$ & $2.545 \times 10^{-6}$ \\
$\mathrm{~K}$ & 0.9516 & 0.9829 \\
$\mathrm{Q}_{\mathrm{m}}$ & &
\end{tabular}




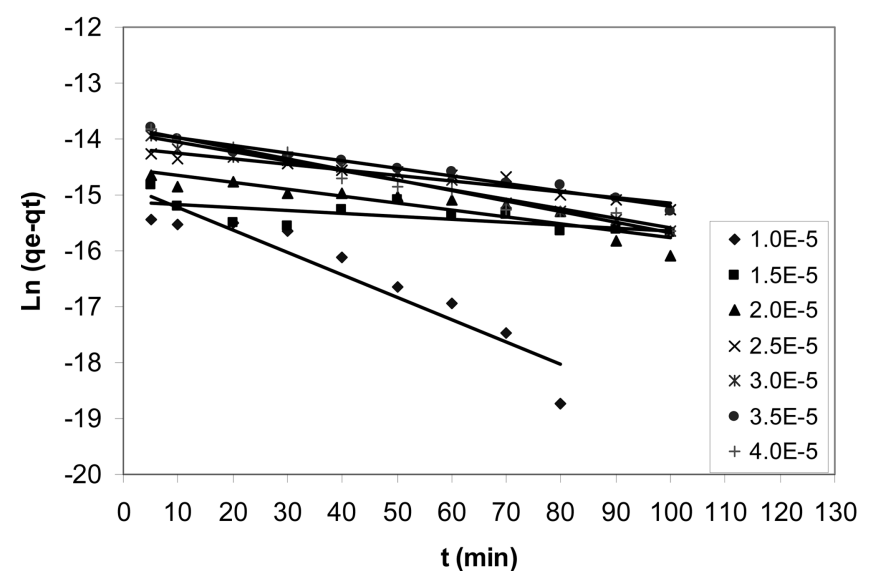

Fig. 6. Fitting of pseudo-first order model for RY15 on ACW different initial concentration.

$\mathrm{mol}), \mathrm{q}_{\max }$ is the maximum adsorption capacity $(\mathrm{mol} / \mathrm{g}), \mathrm{K}_{\mathrm{F}}$ is adsorption capacity unit concentration, $1 / \mathrm{n}$ is adsorption intensity, $B=R T / b$, $\mathrm{R}$ is the gas constant, $\mathrm{b}$ is Temkin isotherm constant, $\mathrm{T}$ is the absolute temperature $(\mathrm{K}), \mathrm{A}$ is the Temkin isotherm constant $(\mathrm{L} / \mathrm{mol}), \mathrm{K}$ is a constant related to the adsorption energy $\left(\mathrm{mol}^{2} / J^{2}\right), \mathrm{Q}_{\mathrm{m}}$ is the theoretical saturation capacity $(\mathrm{mol} / \mathrm{g})$ and $\varepsilon$ is the Polanyi potential. According to Langmuir, Freundlich, Temkin and D-R plots for both dyes, empirical constants to be determined from the intercept and slop of the linear regression. A list of the parameters obtained together with $\mathrm{R}^{2}$ values are given in Table 2. The results indicate that the Temkin model is the best fit model for the adsorption of RY15 onto ACW and D-R model resulted into the best fit the other isotherms for RB5.

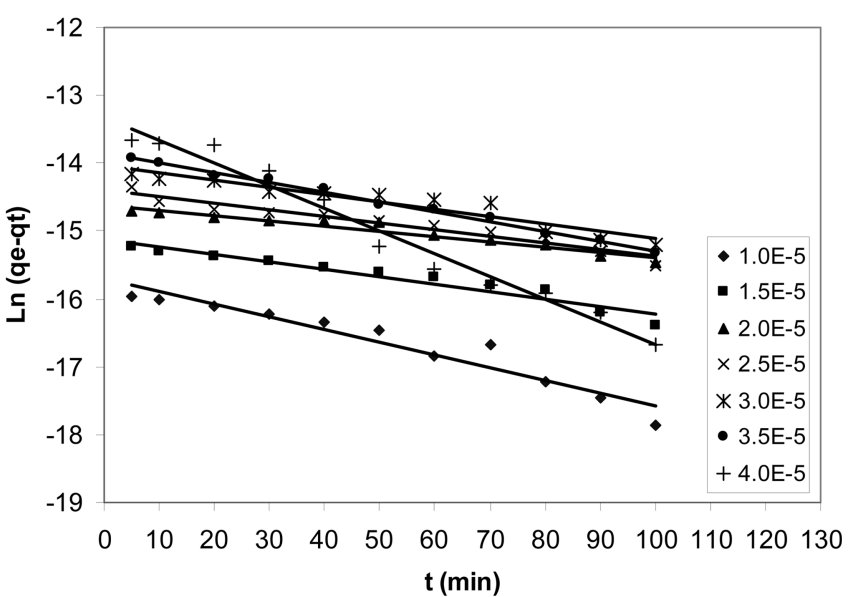

Fig. 7. Fitting of pseudo-first order model for RB5 on ACW different initial concentration.

\subsection{Adsorption kinetics}

In order to examine the controlling mechanism of the adsorption process, pseudo-first order and pseudo-second order equations were used to test the experimental data. Pseudo-first order equation of Lagergren based on solid capacity is given by [22]:

$$
\ln \left(q_{e}-q_{t}\right)=\ln q_{e}-k_{1} t
$$

Where $\mathrm{q}_{\mathrm{t}}$ is the amount of dye adsorbed $(\mathrm{mol} / \mathrm{g})$ at time $\mathrm{t}$, $\mathrm{k}_{1}$ the equilibrium rate constant of pseudo-first order kinetics $\left(\mathrm{min}^{-1}\right)$ and $\mathrm{t}$ is the constant time (min). According to Eq. (9) the plots of $\operatorname{Ln}\left(q_{e}-q_{t}\right)$ vs. t (Figs. 6 and 7) for the

Table 3. Kinetics Constants for Pseudo-first and Pseudo-second Order Models

\begin{tabular}{|c|c|c|c|c|c|c|}
\hline \multicolumn{2}{|c|}{ Dye types and } & \multicolumn{2}{|c|}{ pseudo-first order } & \multirow[b]{2}{*}{$\mathrm{k}_{2} \times 10^{-3}$} & \multicolumn{2}{|c|}{ pseudo-second order } \\
\hline $\mathrm{C}_{0} \times 10^{5}(\mathrm{M})$ & $\mathrm{q}_{\text {eæexp }} \times 10^{+6}$ & $\mathrm{~K}_{1} \times 10^{+3}$ & $\mathrm{R}^{2}$ & & $\mathrm{q}_{\text {ex cal }} \times 10^{+6}$ & $\mathrm{R}^{2}$ \\
\hline \multicolumn{7}{|l|}{ RY15 } \\
\hline 1.0 & 0.997 & 5.4 & 0.8863 & 75.88 & 0.586 & 0.9975 \\
\hline 1.5 & 1.486 & 9.8 & 0.4308 & 86.02 & 0.807 & 0.9973 \\
\hline 2.0 & 1.982 & 12.3 & 0.826 & 95.03 & 1.171 & 0.9951 \\
\hline 2.5 & 2.475 & 13.5 & 0.9228 & 116.0 & 1.487 & 0.9954 \\
\hline 3.0 & 2.971 & 17.1 & 0.9703 & 219.8 & 1.844 & 0.9963 \\
\hline 3.5 & 3.387 & 18.7 & 0.9688 & 481.3 & 1.841 & 0.9980 \\
\hline 4.0 & 3.648 & 39.8 & 0.9713 & 557.7 & 2.253 & 0.9987 \\
\hline \multicolumn{7}{|l|}{ RB5 } \\
\hline 1.0 & 0.402 & 7.80 & 0.9278 & 38.00 & 0.204 & 0.9927 \\
\hline 1.5 & 0.900 & 9.90 & 0.9386 & 74.57 & 0.525 & 0.9953 \\
\hline 2.0 & 1.402 & 10.8 & 0.9425 & 95.17 & 0.745 & 0.9950 \\
\hline 2.5 & 1.887 & 10.9 & 0.9446 & 157.5 & 1.058 & 0.9965 \\
\hline 3.0 & 2.360 & 14.5 & 0.9036 & 198.2 & 1.419 & 0.9919 \\
\hline 3.5 & 2.790 & 18.6 & 0.9934 & 293.3 & 1.615 & 0.9966 \\
\hline 4.0 & 3.166 & 33.5 & 0.9740 & 435.2 & 1.745 & 0.9945 \\
\hline
\end{tabular}




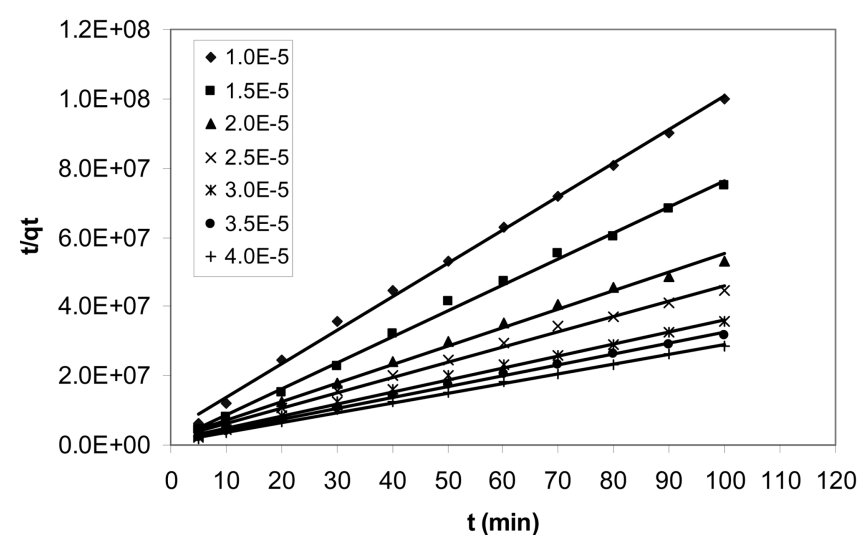

Fig. 8. Fitting of pseudo-second order model for RY15 on ACW different initial concentration.

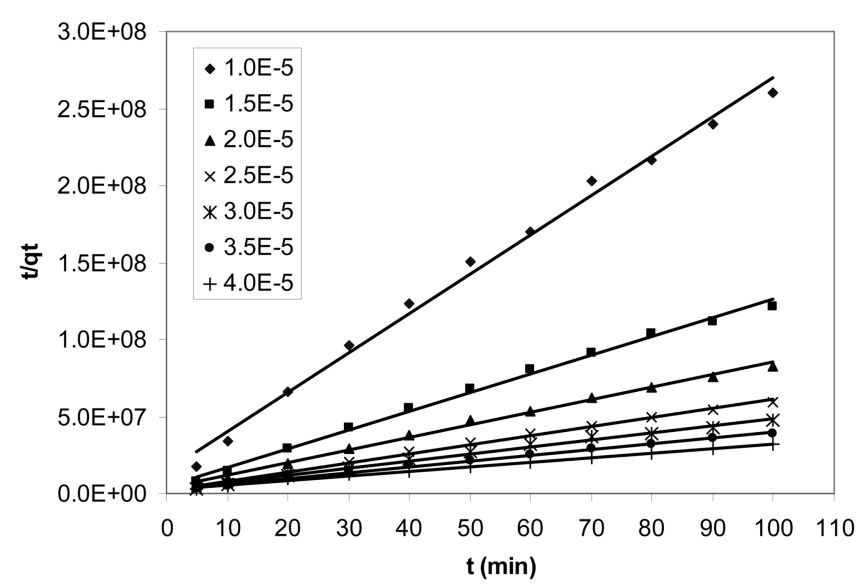

Fig. 9. Fitting of pseudo-second order model for RB5 on ACW different initial concentration.

adsorption of RY15 and RB5 onto ACW have also been tested to obtain the rate parameters. The $\mathrm{k}_{1}$ and $\mathrm{R}^{2}$ were calculated from these plots and are given in Table 3 .

The pseudo-second order kinetic model [23] is based on adsorption equilibrium capacity and can be expressed as:

$$
\frac{t}{q_{t}}=\frac{1}{k_{2} q_{e}^{2}}+\frac{1}{q_{e}} t
$$

Where $\mathrm{k}_{2}(\mathrm{~g} / \mathrm{mol} \mathrm{min})$ is the rate constant for pseudo-second order adsorption. The intercept and slop of $\frac{t}{q_{t}}$ vs. $t$ (Fig. 8 and 9) were used to calculate the pseudo-second order rate constant $\mathrm{k}_{2}$ and $\mathrm{q}_{\mathrm{e}}$, respectively. These values are given in Table 3.

These results suggest that the adsorption of RY15 and RB5 on ACW may be best described by the pseudo-second order kinetic model with high correlation coefficients. The calculated $\mathrm{q}_{\mathrm{e}}$ values also agreed well with the experimental data. The over all rate of the RY15 and RB5 adsorption process are most likely to be controlled by the chemisorption process for ACW. Similar results have been observed in the adsorption of acid red 57 onto calcined alunite [24,25].

\section{Conclusion}

This study indicates that walnut shell was an effective adsorbent for removal of RY15 and RB5. The data indicates that the adsorption kinetics of dyes on ACW followed the pseudo-second order rate expression and the most favorable adsorption occurred in acidic $\mathrm{pH}$. By comparing the correlation coefficients determined for each linear transformation of isotherm analysis, the Temkin and D-R isotherm models, which fit the experimental data reasonably well, were found to provide the best prediction for the adsorbent of RY15 and RB5. the results of the present investigation indicated that $\mathrm{ACW}$, a low-cost adsorbent could be employed as an alternative to commercial activated carbon for the removal of RY15 and RB5 from aqueous solutions.

\section{References}

[1] Bauer, C.; Jacques, P.; Kalt, A. J. Photochem. Photobiol. A: Chem. 2001, 140, 87.

[2] Chakraborty, S.; De, S.; Basu, J. K.; DasGupta, S. Desalination 2005, 174, 73.

[3] Crini, G. Bioresour. Technol. 2006, 97, 1061.

[4] Hameed, B. H. J. Hazardous Materials 2009, 161, 753.

[5] Ambrosio, S. T.; Campos Takaki, G. M. Biores. Technol. 2004, 91, 69.

[6] Osma, J. F.; Saravia, V.; Couto, S. R. J. Hazardous Materials 2007, 147, 900.

[7] Gupta, V. K.; Jain, R.; Varshney, S. J. Hazardous Materials 2007, 142, 443.

[8] Sanghi, R.; Bhattacharya, B. Color. Technol. 2002, 118, 256.

[9] Malik, P. K. Dyes Pigments 2003, 56, 239.

[10] Han, R.; Ding, D.; Xu, Y.; Zou, W.; Wang, Y.; Li, Y. Bioresour. Technol. 2008, 99, 2938.

[11] Sulak, M. T.; Demirbas, E.; Kobya, M. Bioresour. Technol. 2007, 98, 2590.

[12] Oliveira, L. S.; Franca, A. S.; Alves, T. M.; Rocha, S. D. F. J. Hazardous Materials 2008, 155, 507.

[13] Gupta, V. K.; Mittal, A.; Jain, R.; Mathur, M.; Sikarwar, S., J. Colloid and Interface Science 2006, 303, 80.

[14] Rouquerol, F.; Rouquerol, L.; Sing, K. "Adsorption by Powders and Porous Solids", Academic Press, 1999.

[15] Gong, R.; Li, M.; Yang, C.; Sun, Y. J. Hazardous Materials 2005, B121, 247.

[16] Arami, M.; Limaee, N. Y.; Mahmoodi, N. M.; Tabrizi, N. S. J. Hazardous Materials 2006, B135, 171.

[17] Arami, M.; Limaee, N. Y.; Mahmoodi, N. M. Chemical 
Engineering J. 2008, 139, 2.

[18] Langmuir, I. J. Am. Chem. Soc. 1918, 40, 1361.

[19] Freundlich, H. M. F. J. Phys. Chem. 1906, 57, 385.

[20] Hameed, B. H. J. Hazardous Materials 2009, 162, 344.

[21] Khaled, A.; Nemr, A. E.; El-Sikaily, A.; Abdelwahab, O. Desalination 2009, 238, 210.

[22] Thinakaran, N.; Pulikesi, M.; Sivanesan, S. J. Hazardous
Materials 2008, 151, 316.

[23] Chairat, M.; Rattanaphani, S.; Bremner, J. B. Dyes Pigm. 2005, 64, 231.

[24] Wu, F. C.; Tseng, R. L.; Juang, R. S. J. Hazardous Materials 2001, $B 81,167$.

[25] Ozacar, M.; Sengil, A. L. J. Hazardous Materials, 2003, $9 B, 211$. 